\title{
A social-ecological system evaluation to implement sustainably a biochar system in South India
}

\author{
Stefanie Müller ${ }^{1,2} \cdot$ Norman Backhaus $^{1} \cdot$ Prakash Nagabovanalli $^{3} \cdot$ Samuel Abiven $^{1}$ (iD \\ Accepted: 28 June 2019 / Published online: 7 August 2019 \\ (C) INRA and Springer-Verlag France SAS, part of Springer Nature 2019
}

\begin{abstract}
Biochar has been proposed as a technology to mitigate climate change as well as improving soil fertility, energy production, and organic waste treatment. However, the implementation of such techniques in existing cropping systems requires knowledge about potential adaptation barriers. These adaptation barriers are only partly dependent on expected benefits but are deeply embedded in the place-specific settings and livelihood practices of agricultural communities. An integration of adaptation barriers in the development of biochar system designs has the potential not only to facilitate farmer's decision but also to enhance community resilience and reduce their vulnerability. We propose a holistic methodology that considers communities as socialecological systems. We applied this approach to agricultural communities in two villages with different cropping systems in South India. First, we modeled the social-ecological system of each village, based on qualitative interviews with local farmers, using cognitive mapping. Second, we tested the implementation scenarios of two types of biochar system designs (small-/largescale) and a worst-case failure scenario, which were developed by triangulating theoretical information from literature review with information from qualitative interviews and focus groups. Third, we analyzed the outcome on the resilience and vulnerability of the social-ecological systems to define the place-specific adaptation barriers. We were able to successfully capture for the first time the adaptation barriers of two communities concerning a biochar system implementation. We could show that sustainable biochar system designs not only differ depending on site but also demonstrate particularly the relevance of procedural processes independent of site, such as maintenance of autonomy, provision of participation in planning, or promotion of farmers' cooperatives with regional industries. We are certain that this approach could be used for the setting up of future biochar systems or novel technology in general not only in tropical regions but elsewhere.
\end{abstract}

Keywords Biochar $\cdot$ Agricultural practices $\cdot$ Implementation $\cdot$ Social-ecological systems $\cdot$ Cognitive maps

\section{Introduction}

Biochar has been proposed as a technology to mitigate climate change and enhance soil quality, especially for degraded tropical soils (Coomes and Miltner 2017; Glaser et al. 2002; Jeffery et al. 2017). The implementation of biochar in cropping systems may also enhance farmers' livelihoods by improving their agricultural practices, in particular by

Samuel Abiven

samuel.abiven@geo.uzh.ch

1 Department of Geography, University of Zurich, Zurich, Switzerland

2 Swiss Federal Research Institute WSL, Birmensdorf, Switzerland

3 Department of Soil Science and Agricultural Chemistry, University of Agricultural Sciences, Bangalore, India lowering their dependence on inorganic fertilizer and water irrigation and enabling potential additional income sources in the form of carbon credits and local energy production (Barrow 2012; Lehmann and Joseph 2015).

However, the sustainability of biochar adaptation in farming-based communities in tropical regions remains questionable (Barrow 2012; Frausin et al. 2014; Gwenzi et al. 2015; Leach et al. 2012). Criticisms have been voiced, in particular concerning the heterogeneity of field trial outcomes (Mukherjee and Lal 2014; Shackley et al. 2011). In general, the spatial and temporal variabilities of biochar's effect on yield is high (Ding et al. 2016; Spokas et al. 2012). In a large meta-analysis, Crane-Droesch et al. (2013) observed relative yield changes ranging from about -35 to $+75 \%$ (95\% confidence interval) compared to control soils. This effect also varies with time; biochar's benefits tend to increase with cropping seasons, but this trend remains very heterogeneous. 
At the level of field trials, this variability can be related to soil properties (Ding et al. 2016; Spokas et al. 2012), climate (Jeffery et al. 2017), biochar characteristics (which depend on feedstock and temperature of pyrolysis: Camps-Arbestain et al. 2015; Ding et al. 2016), and application methods (biochar particle size, application technique, mixture of biochar with other soil amendments: Camps-Arbestain et al. 2015). The biochar research community has so far invested much effort in developing a classification system for biochar that enables practitioners to identify the physical requirements for successful biochar production and application in a specific place (Camps-Arbestain et al. 2015). When one considers biochar incorporated into cropping systems, hereafter termed biochar systems, further drivers have to be considered. These include the availability of feedstock, laborers, and capital; the fluctuation of market prices; the value and applicability of the by-products; and acceptance of the technology (Duku et al. 2011; Sohi et al. 2015). These economic, social, and cultural variations are as important as to consider physical requirements for successfully implementing biochar in cropping systems (Abiven et al. 2014).

Few studies in the biochar literature have considered these economic, social, and cultural requirements (Gwenzi et al. 2015; Latawiec et al. 2017), and no research study so far has evaluated the relative relevance of these aspects and whether and how their place-dependent variation effects a farmer's decision to implement a biochar system (Jeffery et al. 2015). Studies only focusing on economic aspects often conclude that a farmer's decision to implement a biochar system is driven mainly by economic returns (Mekuria et al. 2013). More holistic approaches to technology implementation in agriculture have shown that a farmer's decisions to implement a new practice is triggered not only by its economic benefit but also by how easily this new tool can be integrated into an existing set of livelihood practices (Robert et al. 2016; Tang et al. 2013). These livelihood practices are indeed influenced by physical and economic conditions, but they are also rooted in the social and cultural characteristics and dynamics of a given place (Tang et al. 2013). Since every place has its own physical, economic, social, and cultural conditions, characteristics, and dynamics, the adaptation barriers to biochar system implementation vary correspondingly (Jeffery et al. 2015).

The term adaptation barriers is rooted in social science research on vulnerability and resilience and refers to the ability of individuals or communities to cope with dynamic conditions (Smit and Wandel 2006). Applied to technology implementation in agriculture, an overcoming of adaptation barriers implies more than simply acceptance and adoption; it also includes the availability and accessibility of a set of livelihood practices and strategies sufficient to prevent and react to potential unexpected outcomes, such as technology failure (Robert et al. 2016; Smit and Wandel 2006; Tang et al. $2013)$. From this perspective, a biochar system implementation can only be considered sustainable if the place-dependent adaptation barriers and their relation to enhancing or reducing resilience and vulnerability have also been considered. This research paper focuses on these placedependent adaptation barriers to a biochar system implementation in tropical regions. The aim is not only to assess them and define the most relevant ones but also to deduce the implications for a sustainable biochar system implementation for specific places and their characteristic livelihood practices.

To design a biochar system in the tropical regions of South India that anticipates the physical, economic, social, and cultural conditions, characteristics and dynamics of the particular place rather than endures them a posteriori, we applied a social-ecological system approach. This approach offers a well-established theoretical framework to assess and evaluate physical, economic, social, and cultural adaptation barriers with respect to vulnerability and resilience (Adger 2006; Adger and Kelly 1999; Gallopín 2006; Smit and Wandel 2006; Tang et al. 2013). We tested this theoretical approach in two farming villages with different cropping systems in South India, where implementing biochar systems may be possible (e.g., given by availability and suitability of biomass for biochar production) (Fig. 1). Data about the socialecological systems were mainly derived by local knowledge. We gathered this knowledge through qualitative interviews and focus groups with local farmers of the two communities, local scientists, owners of rice mills, jaggery houses, a sugar factory and a fish factory, and members of the local government. We further used cognitive mapping (Özesmi and Özesmi 2004; Vanwindekens et al. 2014) to model a social-ecological system for each village. Then, we tested the implementation of two different types of hypothetical biochar system designs in these social-ecological system models: (i) a small-scale system in which farmers in the village produce the biomass, convert the biomass into biochar, and apply the biochar on their fields

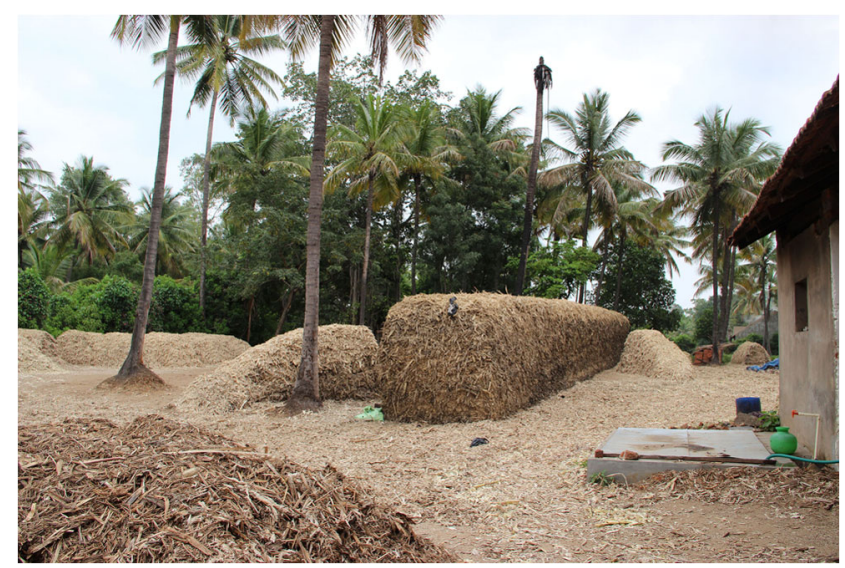

Fig. 1 The remaining organic residues (called bagasse) of jaggery (traditional noncentrifugal sugar) production are stored in the backyards of jaggery houses. Bagasse is mainly used as fuel to heat the vessels in which jaggery is manufactured. Large amounts of bagasse are left, and these could be used for biochar production 
and (ii) a large-scale system, in which the biomass is produced by the farmers, but regional processing companies (e.g., sugar and rice companies) convert the biomass into biochar and sell it back to farmers, who in turn apply it on their fields.

These scenarios, as well as a worst-case failure scenario, developed by triangulating theoretical information from literature review with practical information from the qualitative interviews and focus groups, were then analyzed for its potential outcome on the resilience and vulnerability of the systems. Based on these results, we defined the place-specific adaptation barriers and implications for sustainable biochar system implementation procedures for each of the two villages.

\section{Materials and methods}

\subsection{Research sites}

We selected Chandagalu (Mandya district) and Manoor (Udupi district) in Karnataka, South India to carry out our research. The selection process followed a two-step approach: We started by selecting the districts based on expert interviews with soil scientists in Bangalore. On site, we then selected the specific villages, based on information from agriculture extension workers, local agriculture students, and members of local panchayats (= municipal council).

The representativity of these two sites may be limited to a certain extent, because of time availability on site, field, and data accessibility. However, we believe it provides a relatively good representation of contrasted situations, which allowed us to generate general statements about the effect and relative relevance of adaptation barriers of a place, at least for small-scale farming contexts in tropical regions. We selected sites that are comparable in relation to their type (e.g., size, livelihood activities and practices, feasibility of biochar system implementation) but different in terms of their specific place conditions (e.g., different cropping systems). We selected them using the following selection criteria:

First, the main livelihood activity of the research sites should be small-scale farming and, to be able to capture the system's characteristics in a reasonable period of time, we needed them to be homogenous and relatively small in size. Second, the villages should use different cropping systems and are thus supposed to be different with respect of their specific place conditions, characteristics, and dynamics. We used climate and main crop variety as proxies for cropping systems. Third, biochar-related techniques, such as biogas plants and the use of ashes as soil amendments, should be known and applied by the farmers of the villages in order to facilitate the discussion about the biochar technology, so that the local farmers could quickly understand the issue and access their knowledge about potential implications. Fourth, since we wanted to better understand how a biochar system needs to be designed, so that it anticipates and does not harm or induce negative modifications of the local livelihood practices and activities of farmers and a farming community of a particular place, we needed to assume that an implementation is technically feasible. We therefore selected villages, where an implementation of the biochar technology is potentially possible (e.g., given by availability and suitability of biomass for biochar production).

At the time of fieldwork (Fall 2013), Chandagalu had 3238 inhabitants and Manoor 6381. The main livelihood in Chandagalu is farming (information from the local panchayat). In Manoor, the main livelihood is agriculture and fishing, due to its proximity to the Arabian Sea (information from the local panchayat).

The climate in Chandagalu is classified as equatorial winter dry climate (Aw), and the climate in Manoor is classified as equatorial monsoon climate (Am). In Chandagalu, the average temperature is $20{ }^{\circ} \mathrm{C}$ in winter and $25{ }^{\circ} \mathrm{C}$ in summer. In Manoor, the average temperature is mostly stable at $27{ }^{\circ} \mathrm{C}$. The monsoon affects the climate in both villages and contributes $73 \%$ to the annual precipitation in Chandagalu $(699.8 \mathrm{~mm})$ and $88 \%$ to the annual precipitation in Manoor (3728 mm) (information from the local panchayat). In both villages, three soil types were present: Alfisols, Entisols, and Inceptisols. In Chandagalu, the moisture deficit period ranges between 180 and 220 days (information from local soil scientists). Most farmers thus depend on irrigation (56\%: ICAR Agriculture contingency plan: http://www.icar-crida.res.in/). In Manoor, the moisture deficit (150 days) is not as severe, because it is only seasonal (information from local soil scientists). Major soil issues in Manoor include low nutrient availability, salinity, and erosion. In Manoor, only 33\% of the cultivated land is irrigated (ICAR Agriculture contingency plan: http://www.icar-crida.res.in/).

The main crops cultivated in Chandagalu are sugarcane (Saccharum officinarum), rice (Oryza sativa Indica), and finger millet (Eleusine coracana). Rice and finger millet are mainly produced as food crops, whereas sugarcane is a cash crop. The major crops cultivated in Manoor are rice (Oryza sativa Indica), groundnut (Arachis hypogaea), legumes (Leguminosae spp.), coconut (Cocos nucifera), and areca nut (Areca catechu).

Biochar-related techniques, such as biogas plants and the use of ashes as soil amendments, are known and in use in both villages. In Chandagalu, biogas plants were installed and have been used mainly as electricity source. However, many of them were no longer in use, because the electricity supply in the region had changed. In Manoor, all the biogas plants are used on a regular basis, not only to generate electricity but also for soil amendment; the residual slurry is applied to the fields.

The cropping systems of both villages would potentially allow a biochar system to be implemented, as it is perceived 
by the consulted soil scientists, agriculture extension workers, local agriculture students, and members of local panchayats: In Chandagalu, the bagasse (Fig. 1) remaining from sugar and jaggery (traditional noncentrifugal sugar) production could be used as an organic feedstock for biochar. In jaggery production, this bagasse has been used until now to heat the cooking vessels in which the jaggery is manufactured. Industrial sugar production also creates bagasse, which is used for heating and for electricity generation. However, large quantities of bagasse from jaggery and sugar production remain unused (information from jaggery house and sugar factory owners of Mandya district).

In Manoor, rice hull husk could be an organic feedstock for biochar production. Until now, either these residues have been sold to a local fish factory as fuel or transformed to ashes, which are partly used by farmers as soil inputs or dumped on waste disposal sites, which are often located next to public roads (information from rice mill and fish factory owners of Udupi district).

\subsection{Social-ecological system approach}

To enable statements about adaptation barriers concerning a biochar system implementation in these two research sites, vulnerability, resilience, and sensitivity assessments were conducted. The assessment methods were based on local knowledge. We thereby have not applied a set of pre-defined fixed indicators but used a conceptual framework in order to classify and compare the sampled qualitative data. This conceptual framework was derived from the social-ecological approach:

Our understanding of a social-ecological system was inspired by the conceptual work of Gallopín (2006) and Adger (Adger 2006; Adger and Kelly 1999; Moser 1998; Smit and Wandel 2006). Whereas Gallopín's (2006) conceptualizations enhance understanding at the systemic level, Adger and colleagues' conceptualizations (Adger 2006; Adger and Kelly 1999; Moser 1998; Smit and Wandel 2006) improve understanding at the individual level of a social-ecological system. Our conceptual approach for this study combines Gallopín's (2006) systemic understanding with Adger's (Adger 2006; Adger and Kelly 1999; Moser 1998; Smit and Wandel 2006) understanding of the individual level.

In this study, we considered the community of a village as a social-ecological system with an inherent degree of vulnerability and resilience. For Gallopín (2006), a social-ecological system is characterized by a structure and a function. In relation to Adger's (Adger 2006; Adger and Kelly 1999; Moser 1998; Smit and Wandel 2006) work, we defined the structure of the socialecological system as a construct of collective livelihood practices and routines, which are themselves a product of the overall availability and access to livelihood assets, strategies, and actions. These assets, strategies, and actions can be tangible or intangible, such as human, social, financial, physical, and natural (Moser 1998). We presume that the greater the quantity of assets, strategies, and actions and the better the access to these assets, strategies, and actions, the lower is the inherent vulnerability of the system. Or the lower the quantity of assets, strategies, and actions and the lower the access to these assets, strategies, and actions, the higher is the inherent vulnerability of the system.

According to Gallopín (2006), the system's function is a result of the system's resilience: its capacity to recover from expected and unexpected external hazards, perturbations, and stresses (Gallopín 2006). A system would stop functioning if it were not resilient. With respect to Adger and colleagues (Adger 2006; Adger and Kelly 1999; Moser 1998; Smit and Wandel 2006), proxies for the inherent resilience of a working system are those livelihood assets, strategies, and actions that are particularly important for the functioning of the system. The more a particular asset, strategy, or action is required for maintenance, the higher is its relevance for the resilience and vice versa.

However, systemic resilience is not static and can be modified by external intervention. This transformation is dependent on the sensitivity of the system to the type of external intervention or the threshold to which a system can be modified before it changes its function (Gallopín 2006). A proxy for the system's sensitivity is its adaptive capacity (Berrouet et al. 2018; Gallopín 2006). A highly sensitive system that is facing external interventions, possibly caused by a failure of a biochar system implementation, might has not enough adaptive capacity to prevent a severe transformation of the system's function. A system with a low sensitivity, on the other hand, might has enough adaptive capacity to recover without modification of the system's function. With respect to Adger and colleagues (Adger 2006; Adger and Kelly 1999; Moser 1998; Smit and Wandel 2006), we defined the adaptive capacity of a system by its amount and type of livelihood strategies available to prevent a severe modification of a system caused by biochar failure.

Nonetheless, a systemic understanding of the inherent vulnerability and resilience of a social-ecological system alone is insufficient. As Adger and colleagues have shown (Adger 2006; Adger and Kelly 1999; Moser 1998; Smit and Wandel 2006), a system can be resilient even if not all individuals, groups, or households within the system are invulnerable. This is because not all of them have equal access to livelihood assets, strategies, and actions. For this reason, we considered not only the systemic but also the individual level of a socialecological system, by taking into account in particular the differences in access availability by individuals to relevant livelihood assets. 


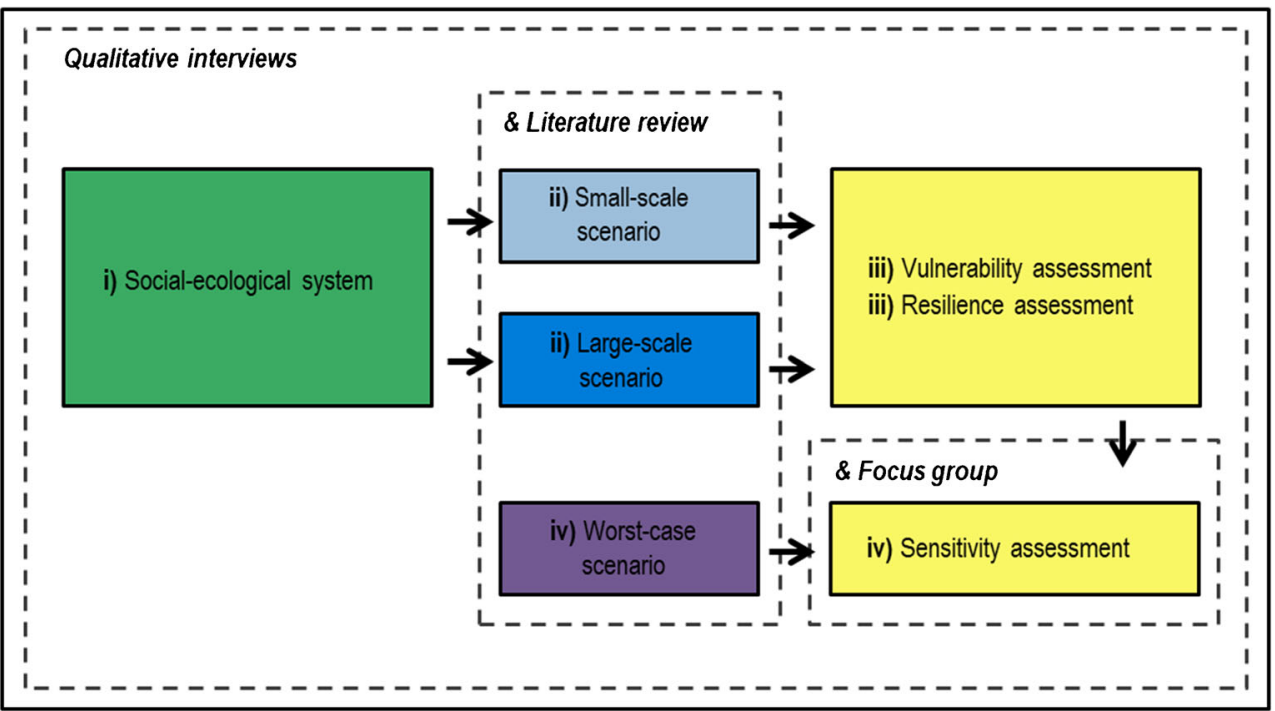

Fig. 2 The research design is based on the social-ecological approach. First, the social-ecological systems of the two villages Chandagalu and Manoor were modeled using data of the qualitative interviews and cognitive mapping (green). Then, a small-scale (light blue), a largescale (dark blue), and a worst-case scenario (purple) based on the data

\subsection{Research design}

Our research design (Fig. 2) follows the social-ecological approach as previously described. To identify adaptation barriers, we needed to assess how a potential implementation of a biochar system would modify the inherent structure and function of the social-ecological system of a particular village. To identify this modification, we took four steps. First, we defined the structure and the function of the socialecological system. Second, we defined which livelihood assets of the system would be affected by different designs of biochar system implementations (large-/small-scale). Third, we assessed the relative impacts of the implementations on resilience and vulnerability by evaluating how they would alter the systems and affect the individuals: How important is any specific livelihood asset for the function of the system (resilience), and how accessible is the asset: Is it accessible to everyone or just a few (vulnerability)? Fourth, we tested the sensitivity of the social-ecological system by analyzing how the systems and individuals respond to a worst-case failure scenario, by assessing their adaptive capacity.

To operationalize our research design, we applied various data sampling and data analysis methods. First, we reviewed 25 research and review articles about biochar technology, focusing on the elements, benefits, uncertainties, and risks of biochar system implementation. Second, we conducted 59 qualitative interviews: 20 interviews with farmers in Chandagalu, coded as C: P1-P20; 17 interviews with farmers in Manoor, coded as M: P21-P37; 15 interviews with local scientists, owners of a rice mills, a sugar factory, jaggery houses, and a fish factory; and 7 members of the local government of the qualitative interviews and a literature review was developed. For the small- and large-scale scenarios, an assessment of vulnerability and resilience was carried out (yellow). For the worst-case scenario, a sensitivity assessment was performed during a focus group (yellow)

(panchayat, agricultural extension services). The interviews focused on three main topics: (i) livelihood activities and strategies applied to deal with expected and unexpected events, (ii) expected and unexpected hazards, perturbations, and stresses experienced while introducing and applying new agricultural technologies and practices; and (iii) biochar systems and perception of their adaptation potential. Third, we conducted four focus groups with 15 participants in each (two in Chandagalu and two in Manoor), where the participants were presented with the potential risks of a biochar system, which we derived from the literature review and the interview results. Each focus group began with a trade-off-game, which was followed by a brief individual standardized questionnaire and a group discussion.

The structure and function of the social-ecological systems were defined by a set of livelihood assets and their relation to each other. We used the qualitative data of the interviews and the cognitive mapping method to construct these socialecological systems. The cognitive mapping method is comparable with the axial coding step of grounded theory, in which core concepts, derived by a coding process from qualitative interview data, are set in relation to each other. We chose this method, because it has been argued that cognitive mapping is especially useful for dealing systematically with large qualitative data sets of individuals or groups perceptions of social reality, without significantly reducing their information content (Eden 1994; Özesmi and Özesmi 2004). Furthermore, the cognitive mapping method has so far often been used for sustainable problem-solving and empowerment in decisionmaking processes of local individuals and groups, not only because of its potential to integrate local knowledge but also 
because of its ability to visualize social realities using graph theory (Eden 1994; Özesmi and Özesmi 2004).

With the use of graph theory the cognitive mapping method visualizes individuals and groups' perceptions of social realities by mirroring them as a network of nodes and lines (Gray et al. 2014; Özesmi and Özesmi 2004; Vanwindekens et al. 2014). Technically, a cognitive map consists of a binary matrix that contains a number of relational and nonrelational concepts (or nodes) $(0=$ no relation, $1=$ relation $)$ and is visualized with a visualization software (such as fc mapper: available at http://www.fcmappers.net/joomla/). Usually, a weight is identified for each connection (or line) (Özesmi and Özesmi 2004; Vanwindekens et al. 2014). In this study, the connections were unweighted; we chose not to weight the connections so as to stay as close as possible to the information provided by the local individuals and prevent the inclusion of bias arising from our prior knowledge. For Chandagalu, a total of 813 of connections and 107 livelihood assets (or concepts) were defined: 26 human assets, 32 social assets, 9 financial assets, 29 physical assets, and 12 natural assets. For Manoor, 862 connections and 105 assets were defined: 28 human assets, 28 social assets, 10 financial assets, 27 physical assets, and 12 natural assets.

Each asset is defined by its centrality and its indegree and outdegree values. The centrality is the sum of ingoing (= indegree) and outgoing (= outdegree) lines. It is assumed that the greater the centrality of the asset, the more central the asset is for the structure and function of the social-ecological system. We used this value to determine the specific conditions, characteristics, and dynamics of the social-ecological systems. The outdegree value is the sum of outgoing lines of a specific asset. It represents the relative influence of this specific asset on the system's resilience. The higher the number of the outgoing lines, the more important the asset is for the inherent resilience of the system, and the more pressure on this asset may occur, the greater is the chance of an alteration in the system's resilience. The indegree value is the sum of the ingoing lines of a specific asset. We used it as a proxy for vulnerability. A low number of ingoing lines indicate that a specific asset is not easily accessible or is only accessible to a few people. A high number of ingoing lines, however, not merely imply that the asset is easily accessible: it may also indicate that this specific asset is of high relevance for the farmers' livelihood. Altering access to this asset or increasing demand for this asset increases the chance of changing its relevance. Depending on the type of alteration, this can have a positive or a negative impact on the farmers' vulnerability.

Since the social-ecological systems differ in the numbers of assets and connections, we needed to standardize the centrality, indegree, and outdegree values to make them comparable. We calculated the proportion in percentages of the resulting values to a hypothetical social-ecological system where all assets are interlinked with each other. In the results section, we indicated them as follows: $\mathrm{C}$ for Chandagalu followed by the percentage and by $\mathrm{M}$ for Manoor followed by the percentage. To verify the results of the cognitive mapping method, we traced back the paths of the most relevant assets and connections by reviewing the associated statements in the interview transcripts.

To assess the adaptation barriers of a biochar system implementation of these two different social-ecological systems, we developed a small-scale and a large-scale biochar system design and introduced them into each social-ecological system. We thereby used the same kind of biochar system designs for both villages to enable the comparison of the different implementation scenarios. The biochar system designs are defined by three phases as proposed by Sohi et al. (2015): (i) a biomass phase, where biomass is produced and collected, transported to the pyrolysis facility and prepared for pyrolysis, for example by reducing in size and drying; (ii) a conversion phase, where the biomass is transformed by pyrolysis to biochar and bio-energy products; and (iii) an application phase, where biochar is transported to the farm and applied to the field. By a combined consideration of the results of the literature review and the data of the qualitative interviews, we defined for each of the designs (large-/small-scale) the livelihood assets that are needed or affected by an implementation (Table 1). To determine the outcome of the implementation scenarios, we analyzed the identified assets as needed and affected by small-scale and large-scale biochar system and their relative relevance for the resilience and vulnerability of the two social-ecological systems. For this assessment, we again used the outdegree value as a proxy for resilience and the indegree value as a proxy for vulnerability and verified them by tracing back the outcomes and comparing them with the associated interview data as we did to validate the socialecological system.

Since we conducted a pre-implementation study, it was not possible to directly assess the sensitivity of a system concerning the potential external hazards, perturbations, and stresses, which could be caused by a biochar system implementation. Therefore, we assessed the differences of adaptive capacities by presenting the farmers a worst-case failure scenario of a biochar system implementation, followed by an assessment of the perception of severity and type and amount of mentioned strategies to cope with it. The worst-case failure scenario is thereby also a product of the literature review and the interview data analysis and is the same for both villages to enable comparison between them.

Eight potential risks were defined by comparing the results of the literature review and the perceived risks mentioned by the farmers: (i) no good yield, (ii) unsuitable technology, (iii) fertilizer costs increase, (iv) soil becoming spoilt, (v) unsupportive governmental scheme, (vi) youngsters moving to the city, (vii) no laborers, and (viii) increase in health costs. In four focus groups (two in Chandagalu and two in Manoor), 
Table 1 Perceived potential impacts of small-scale (light blue) and large-scale biochar (dark blue) systems for each phase (biomass phase $=$ $\mathrm{B}$, conversion phase $=\mathrm{C}$. and application phase $=\mathrm{A}$ ) on the livelihood practice of farmers in Karnataka, South India, based on a literature review and qualitative interview data

\begin{tabular}{|c|c|c|c|c|c|c|c|c|c|c|c|}
\hline & \multicolumn{6}{|c|}{ Small-scale } & \multicolumn{5}{|l|}{ Large-scale } \\
\hline & \multicolumn{3}{|c|}{ Impact to } & \multicolumn{3}{|c|}{ Access needed to } & \multicolumn{2}{|l|}{ Impact to } & \multicolumn{3}{|c|}{ Access needed to } \\
\hline & B & C & $A$ & B & C & A & C & A & B & C & $A$ \\
\hline \multicolumn{12}{|l|}{ Human assets } \\
\hline \multicolumn{12}{|c|}{ Farm management } \\
\hline \multicolumn{12}{|l|}{ Laborers } \\
\hline \multicolumn{12}{|l|}{ Trust } \\
\hline \multicolumn{12}{|l|}{ Mobility } \\
\hline \multicolumn{12}{|l|}{ Social assets } \\
\hline \multicolumn{12}{|l|}{ Government } \\
\hline \multicolumn{12}{|l|}{ Market } \\
\hline \multicolumn{12}{|l|}{ Scientists } \\
\hline \multicolumn{12}{|l|}{ Land rights } \\
\hline \multicolumn{12}{|l|}{ Financial assets } \\
\hline \multicolumn{12}{|l|}{ Income } \\
\hline \multicolumn{12}{|l|}{ Capital/ savings } \\
\hline \multicolumn{12}{|l|}{ Market prices } \\
\hline \multicolumn{12}{|l|}{ Natural assets } \\
\hline \multicolumn{12}{|l|}{ Irrigation system } \\
\hline \multicolumn{12}{|l|}{ Energy } \\
\hline \multicolumn{12}{|l|}{ Manure } \\
\hline \multicolumn{12}{|l|}{ Fertilizer } \\
\hline \multicolumn{12}{|l|}{ Organic waste } \\
\hline \multicolumn{12}{|l|}{ Transportation } \\
\hline \multicolumn{12}{|l|}{ Land size } \\
\hline Natural assets & & & & & & & & & & & \\
\hline Soil quality & & & & & & & & & & & \\
\hline Climate & & & & & & & & & & & \\
\hline Yield & & & & & & & & & & & \\
\hline Land & & & & & & & & & & & \\
\hline Sugarcane/ Rice & & & & & & & & & & & \\
\hline
\end{tabular}

we first presented these risks to the farmers by introducing the biochar technology through a trade-off game. This trade-off game simulated a range of investment scenarios, including the worst-case outcomes. In the subsequent discussions, we asked the farmers about the reasons for their investment decisions and the strategies they would apply if faced with a worst-case outcome. We additionally distributed a standardized questionnaire to the participants of the focus group. With the help of local agriculture students and agricultural extension service workers, the farmers answered structured questions about their perception of severity of potential risks that may are caused by an implementation of a biochar system. We then used the farmers' estimation of their capacity to cope with a substantial risk induced by a biochar system implementation failure to identify the differences in sensitivity of each village.

\section{Results and discussion}

\subsection{Cognitive mapping facilitates to detect similarities and differences between the two social-ecological systems}

The cognitive maps of the social-ecological systems (Fig. 3) show that certain assets have similarly high values for centrality in both social-ecological systems. In both villages, the supply of laborers is perceived as not sufficient to meet demand. Laborers (C 21.2\%/M 24.5\%) are needed by the farmers for several activities, and demand is particularly high during planting and harvesting. For some of the farmers, shortage of labor availability and increasing wages have forced them to give up farming (C: P14). As a result of this 
Fig. 3 Social-ecological systems of (a) Chandagalu and (b) Manoor that are generated using the cognitive mapping method (as described in the material and method section). Each cognitive map shows the distinct set of livelihood assets (human, social, financial, physical, and natural) of each village and how they relate to each other. The assets are represented by colored circles and the relations by arrows (or lines). The larger the circle of an asset, the higher is its centrality value (or relevance for the system). The color code is red = human assets, orange $=$ social assets, yellow $=$ financial, blue $=$ physical assets, and green $=$ natural assets

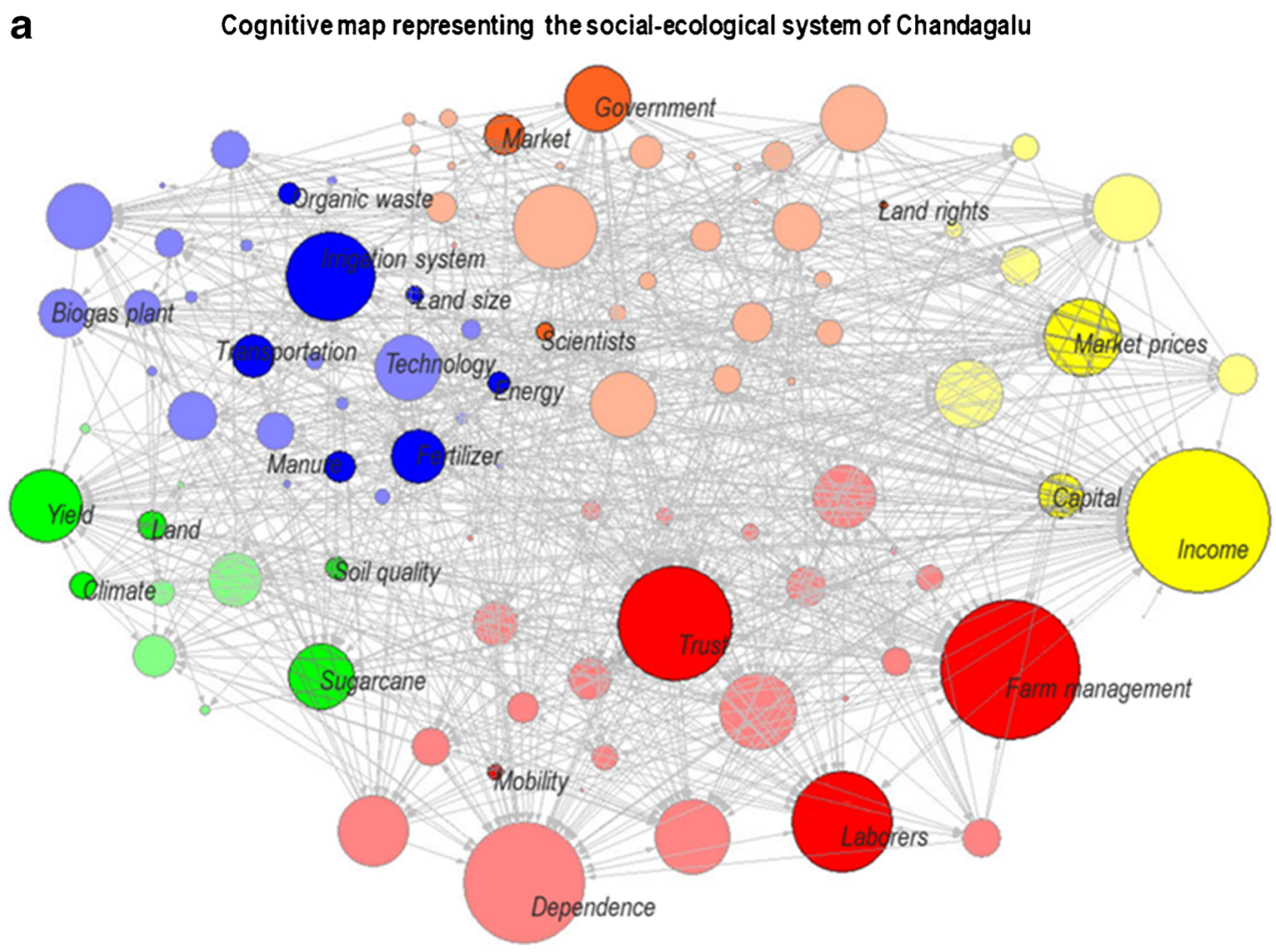

b Cognitive map representing the social-ecological system of Manoor

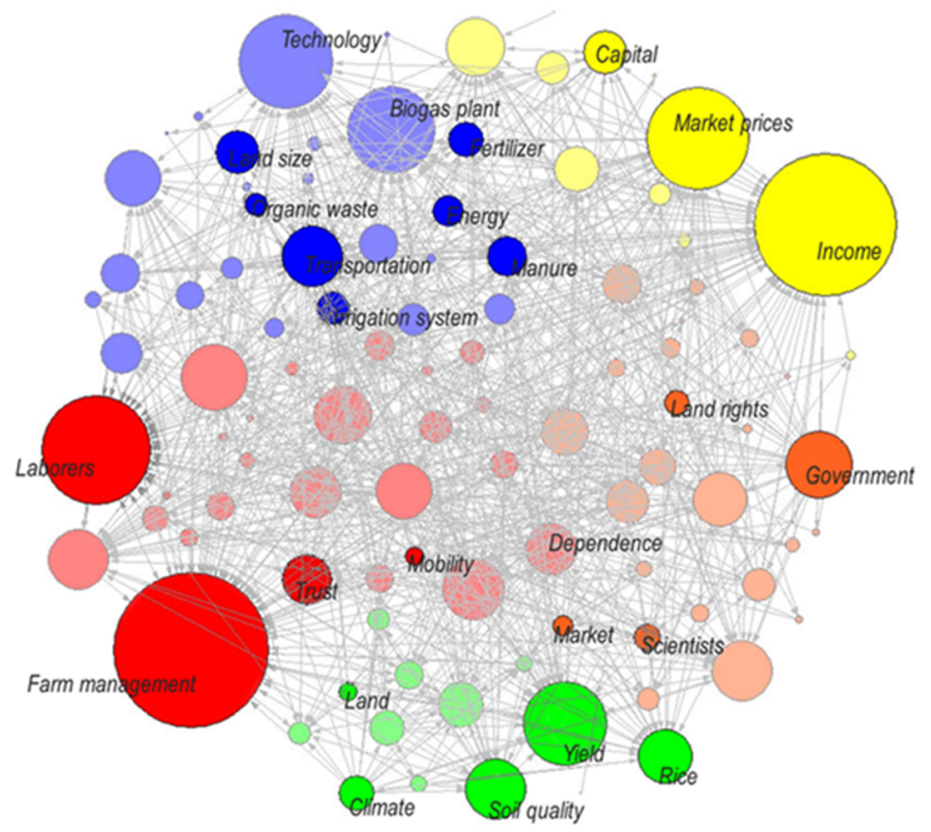

shortage, most of the farmers rely on the support of their family members and neighbors. The social-ecological systems show that this social asset aid $(\mathrm{C} 16.1 \% / \mathrm{M} 16.4 \%)$ is relatively important for the structure and function of the system in both villages. Other important assets in both social-ecological systems are income (C 33.5\%/M 33.2\%), market prices (C $17.5 \% / \mathrm{M} 20.2 \%$ ), and yield (C 17.9\%/M 20.7\%). The high centrality value of these assets is not surprising, because both social-ecological systems represent the livelihood of agricultural-based communities.

Despite differing physical conditions, differences within the social-ecological systems are greater for intangible assets (human, social, cultural), such as farm management. Farm management depends on the management capabilities of a farmer. In both villages, a variety of farming practices were mentioned (e.g., sowing, watering, observing, controlling 
weed, fertilizing, cropping, burning, and obtaining information). Farm management (C 30.2\%/M 39.4\%) has a high centrality value in both villages, but the centrality value of farm management in the social-ecological system of Manoor is $9.2 \%$ higher due to a greater diversity of farm management practices (e.g., use of slurry as soil amendment, use of nontraditional agricultural technologies such as drum seeders, regular farmer meetings).

This is further reflected by the differences in centrality value of technology (C 11.8\%/M 22.6\%), biogas plant (C

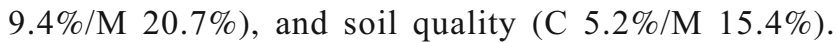
Consistent with the greater diversity of general farm management strategies, farmers in Manoor knew and applied a greater range of farming practices to improve the quality of their soils. Moreover, farmers in Manoor expressed greater openness to the use of technology (M: P23), as is demonstrated by their higher general valuation of biogas plant utility. The plant is used not only to generate electricity; the residual slurry is also used by many farmers as fertilizer for their fields (M: P21; P22; P27). In Chandagalu, many biogas plants no longer operate, and their utility is contested (C: P9; P11).

Farmers in Manoor, overall, had generally positive experiences using nontraditional technologies. As a result, they show a stronger tendency to trust than farmers in Chandagalu, where trust is highly alterable (indegree value of trust: C $28.3 \% / \mathrm{M} 11.5 \%$ ). This lack of trust in Chandagalu has been caused, firstly, by negative experience with the introduction of nontraditional technologies and the belief that a yield failed because of new techniques (C: P20). The second cause is a resource conflict: In Chandagalu, access to an irrigation system (C $15.6 \% / \mathrm{M} 8.7 \%)$ is crucial for profitable cultivation. Over half of the cultivated area $(56 \%)$ is irrigated (ICAR Agriculture contingency plan: http://www. icar-crida.res.in/) by the Cauvery canal, (information from local soil scientists) which is fed by the Krishnarajasagar dam and reservoir. The Cauvery River rises in the Western Ghats and flows through the Indian states of Karnataka, Tamil Nadu, and Kerala until it reaches the Bay of Bengal. In the last 800 years, water disputes between the border states have frequently compromised the water security of Chandagalu (Amjath Babu 2008). At the time of field work, the canal was once more the topic of dispute, exacerbated by canal repair work, which dried up this irrigation source for many of the farmers (C: P01; P04; P13; P14; P17; P18).

Another striking difference highlighted by the cognitive maps of the social-ecological systems of Chandagalu and Manoor is the difference in dependence (C $25.5 \% / \mathrm{M}$ $12.5 \%)$. Farmers in Chandagalu perceive themselves as highly dependent, because they perceive that numerous livelihood activities depend on governmental support (indegree value: C 39.6\%). Manoor experiences a different situation: farmers perceive themselves as having more autonomy in their livelihood activities (indegree value: M 9.6\%), although the overall relevance of dependence is higher for the system's function in Manoor than in Chandagalu (Outdegree value: C $11.3 \% / \mathrm{M}$ $15.4 \%$ ). These differences in perception of autonomy can be explained by the experience of self-efficacy of farmers in Manoor, who perceive themselves as more capable of controlling the outcome of their farm management activities than farmers in Chandagalu (M: P22; P23; P24; P32). Farmers in Chandagalu perceive themselves to be more dependent on external influences, which they consider they cannot actively change (C: P06; P14; P17).

Reviewing the statements in the interview transcripts and tracing back the paths of the livelihood assets and connections of the social-ecological systems validates the two socialecological system models. In this sense, the validity analysis shows that the two social-ecological systems represent the villages accurately. However, this also shows that they are very place-specific and cannot be applied for other places. This suggests that cognitive mapping is indeed a useful method for connecting information and knowledge from different sources, such as 59 qualitative interviews (Özesmi and Özesmi 2004), to reflect the conditions, dynamics, and characteristics of a specific place. It also supports the selection of the issues most relevant to the research foci without losing the complexity of the context (Eden 1994; Özesmi and Özesmi 2004). Nevertheless, its construction and interpretation rely strongly on local knowledge, which results in a lack of generalizability and transparency for nonlocals.

\subsection{A biochar system effects vulnerability and resilience differently depending on implementation size and the initial situation}

In both villages and for both scenarios (small-/large-scale), a generally positive outcome in resilience can be expected with the introduction of a biochar system. Biochar can increase resilience by increasing the soil quality and the yield, lowering the dependence on irrigation systems, manure, and fertilizer and by providing activities to mitigate climate change (Table 2). Due to the differing climatic situations of Chandagalu (Aw) and Manoor (Am), the effect on resilience is higher for irrigation system (C 18.9\%/M 9.6\%) and climate (C 17.3\%/M 12.3\%) in Chandagalu and for soil quality in Manoor (C 7.6\%/M 18.3\%) (Table 2).

However, the resilience assessment shows that small-scale biochar system implementation has certain advantages: A small-scale biochar system is expected to have a greater positive impact on the diversity of farm management practices and on income than a large-scale system would. These assets are crucial for systemic resilience in both villages (Fig. 3). Moreover, if the government promotes small-scale implementation by schemes perceived as supportive (C: P3; P6; P14; P16; P17/M: P25), it can be expected to enhance systemic 
Table 2 Impacts of a biochar system dependent on the initial situation in each village.

\begin{tabular}{|c|c|c|c|c|c|c|c|c|c|}
\hline \multicolumn{5}{|c|}{ a) Perceived effect of a biochar system on the resilience } & \multicolumn{5}{|c|}{ b) Perceived effect of a biochar system on the vulnerability } \\
\hline & Small-scale & Large-scale & Chandagalu & Manoor & & Small-scale & Large-scale & Chandagalu & Manoor \\
\hline Farm management & & & $20.8 \%$ & $26.0 \%$ & Farm management & & & $39.6 \%$ & $52.9 \%$ \\
\hline Laborers & & & $20.8 \%$ & $19.2 \%$ & Laborers & & & $21.7 \%$ & $29.8 \%$ \\
\hline Government & & & $19.8 \%$ & $28.9 \%$ & Trust & & & $28.3 \%$ & $11.5 \%$ \\
\hline Income & & & $17.0 \%$ & $16.3 \%$ & Mobility & & & $2.8 \%$ & $0.0 \%$ \\
\hline Irrigation system & & & $18.9 \%$ & $9.6 \%$ & Government & & & $3.8 \%$ & $0.7 \%$ \\
\hline Manure & & & $8.5 \%$ & $6.7 \%$ & Scientists & & & $0.0 \%$ & $2.9 \%$ \\
\hline Fertilizer & & & $7.5 \%$ & $6.7 \%$ & Land rights & & & $0.0 \%$ & $0.0 \%$ \\
\hline Energy & & & $4.7 \%$ & $3.9 \%$ & Market & & & $6.6 \%$ & $1.9 \%$ \\
\hline Soil quality & & & $7.6 \%$ & $18.3 \%$ & Capital & & & $5.7 \%$ & $7.7 \%$ \\
\hline Yield & & & $12.3 \%$ & $14.4 \%$ & Market price & & & $13.2 \%$ & $20.2 \%$ \\
\hline \multirow[t]{8}{*}{ Climate } & & & $17.3 \%$ & $12.3 \%$ & Land size & & & $0 \%$ & $1.9 \%$ \\
\hline & & & & & Transportation & & & $8.5 \%$ & $7.7 \%$ \\
\hline & & & & & Energy & & & $4.7 \%$ & $8.5 \%$ \\
\hline & & & & & Organic waste & & & $4.7 \%$ & $8.7 \%$ \\
\hline & & & & & Sugarcane/ Rice & & & $16.0 \%$ & $17.3 \%$ \\
\hline & & & & & Climate & & & $0.0 \%$ & $1.0 \%$ \\
\hline & & & & & Land & & & $0.0 \%$ & $0.0 \%$ \\
\hline & & & & & Soil quality & & & $2.8 \%$ & $12.5 \%$ \\
\hline
\end{tabular}

The colors indicate the expected relative alteration of the particular livelihood asset: brown $=$ high alteration $(>5 \%)$, orange $=$ medium alteration $(1-5 \%)$, yellow $=$ small alteration $(<1 \%)$, red $=$ exceptionally high value $(=7 \%)$. The numbers of column 3 and 4 show the relative relevance of each livelihood asset for the inherent (a) resilience and (b) vulnerability in the social-ecological systems. More than 5\% of observed difference between the villages is indicated by bold numbers. The results of the table stand not on its own. These results are only valid while considering the qualitative interview data

resilience, particularly in Manoor (C 19.8\%/M 28.9\%) (Table 2).

A factor crucial to the implementation of a biochar system is the relatively high demand on laborers. In both villages, the need for laborers is perceived as high (Fig. 3). Since the implementation of a biochar system might increase the pressure on labor availability, this factor can be expected to produce a potentially negative outcome for systemic resilience, especially for large-scale implementations (Table 2).

However, the vulnerability assessment relativizes the potentially more positive outcome of a small-scale biochar system implementation. Overall, it can be observed that a smallscale biochar system requires that farmers (despite the need for laborers) have more access to livelihood assets than a large-scale biochar system (Table 1). Small-scale biochar systems demand more access to farm management, capital, government, scientists, and land rights than large-scale versions (Table 1). This most probably limits the success of a smallscale implementation, because apart from farm management, farmers do not perceive that they have sufficient access to capital, government, scientists, and land rights needed for successful small-scale implementation (Table 2).

Market situation, market prices, land size, transport, climate, soil quality, and trust are equally important for both implementation types (Table 1). Access to trust and market prices remains low in both cases (Table 2). Access to market prices is perceived as alterable to a certain degree by the farmers, because a farmer usually follows the market prices and sells or buys at the best market prices. However, the market situation is perceived as largely beyond the control of farmers (Table 2).

Access to mobility, energy, organic waste, sugarcane, rice, and topography of the land is perceived by the farmers of both villages to be of lower relevance than other assets for a biochar system implementation (Table 1). Nonetheless, the vulnerability assessment shows that these assets are not easily accessible by everyone. The differences in accessibility to organic waste (or organic leftovers of sugar, jaggery, and rice production) and sugarcane/rice are particularly interesting (Table 2). Whereas sugarcane and rice fields are accessible to most of the farmers, not all of them have access to organic waste (Table 2). In Chandagalu, access to organic waste is even $\mathrm{C}$ $8.7 \%) / C ~ 8.7 \%)$. In Chandagalu, the organic waste of jaggery and sugar production, termed bagasse, is stored either at the jaggery houses in the village or at the sugar factories in the city (information from jaggery house and sugar factory owners of Mandya district). Thus, only a particular group of people has direct access to this bagasse. Moreover, they already have 
alternative uses for it, such as heating and electricity production (information from jaggery house and sugar factory owners of Mandya district). In Manoor, access to the organic residues of rice production, termed rice hull husk, is also limited, although it is potentially accessible to more people. This is mainly because, so far, rice hull husk has not been converted into a profitable product. Much of the rice hull husk is converted into ashes, which often remains unused and hence is disposed of at the roadside (information from rice mill owner of Udupi district).

The results of the resilience and vulnerability assessments demonstrate that there are differences between small- and large-scale biochar systems. The resilience assessment clearly indicates that the implementation of a small-scale biochar system could have a significant positive impact on the resilience of the social-ecological systems. This result supports arguments advanced by Barrow (2012) and McHenry (2009), who in general recommend small-scale implementation directly in the village or its environs and not commercial or industrial production. However, as the vulnerability assessment shows, access to the assets required for a small-scale biochar system is in particular difficult to achieve, which is not the case for a large-scale biochar system, for which the assets required are all easier to access except for laborers.

At first sight, the results of the resilience and vulnerability assessment used in this study to estimate the potential for the adaptation of biochar systems in the tropics confirm the oftenillustrated relation between economic profit and higher change of adaptation (Mekuria et al. 2013). Where the potential benefits of a biochar system, such as improved soil quality, increased yield, and fertilizer substitution, positively affect the farmers' income, the system's resilience would definitely increase. However, in contrast to much existing biochar literature, our analysis of the social-ecological systems resilience and vulnerability moreover shows that economic profits are not the strongest requirement for an adaptation of a biochar system. Adaptation barriers arise foremost due to procedural aspects or the manner in which a biochar system is implemented. The farmers of both places demonstrate a generally high dependence on governmental bodies (Table 2), so the impact of governmental decisions on the resilience of the communities is perceived as high (C $19.8 \% / \mathrm{M} 28.9 \%)$. At the same time, access to governmental decisions is perceived as very low $(\mathrm{C} 3.8 \% / \mathrm{M} 0.7 \%)$, which results in places where the perception of dependence is high and pro-active attitude is low (Robert et al. 2016), such as in Chandagalu. In contrast, equally dependent farmers who perceive themselves as highly selfeffective have a more pro-active attitude towards farming, such as farmers in Manoor (Fig. 3). A community whose farmers are rather pro-active may well find it easier to implement a biochar system successfully. Nonetheless, governmental schemes perceived as unsupportive may increase the perception of dependence and lower the perception of autonomy, which seems to be a requirement for pro-active behavior for these farmers (C: P3; P6; P14; P16; P17/M: P25). This shows that it remains especially important to develop governmental schemes that are perceived as supportive, as has similarly been pointed out by Jeffery et al. (2015) and Latawiec et al. (2017). Developing these governmental schemes for biochar systems through inclusive and participatory approaches may be one possibility to fulfill this requirement and at the same time would lower the perception of insufficient access to governmental decisions and thus could enhance instead of reducing the resilience of a village (Adger 2006).

\subsection{Low reactive strategies facing risks of a biochar system implementation in both villages}

Despite the more pro-active attitude and consequently potentially easier implementation of a biochar system in Manoor, the worst-case scenario indicates that this village has a higher sensitivity to a failure than Chandagalu. Farmers in Manoor might have more pro-active adaptation strategies (Robert et al. 2016) available to prevent risks (e.g., higher number of farm management practices and soil quality enhancement activities), but a worst-case scenario is perceived as more intrusive by the farmers of Manoor than of Chandagalu (average value of perceived impact of a worst-case scenario: C 3.1/M 3.7) (Fig. 4).

As demonstrated, the shared perception of autonomy is particularly important for the resilience of a social-ecological system. However, the reactive strategies (Robert et al. 2016) applied, while facing a worst-case scenario, tend to reduce rather than increase autonomy. These include the following: taking governmental aid, taking a loan, asking extension services for advice, doing nothing, striking, and asking the authorities for help. The reason why farmers in Chandagalu perceive the worst-case scenario as less intrusive than do farmers in Manoor, although they report the similar reactive adaptation strategies, might be because they continuously face negative experiences, perceive themselves as highly dependent, and are therefore less motivated to maintain a certain level of autonomy (Fig. 3). Farmers in Manoor perceive themselves as highly self-effective, so the loss of autonomy induced by a failure of a novel technology would make them more vulnerable and as a reaction to the increased dependence, less pro-active.

Indeed, the results of this sensitivity assessment have to be judged with caution: First, because of the limited number of workshop participants and, second, because of the low consideration of ecological sensitivity in our applied socialecological approach (Berrouet et al. 2018; Thiault et al. 2018). Ecological system sensitivity was not yet assessed in both villages by applying biogeochemical measurements or experiments. The potential threats of a biochar system failure scenario were derived from an estimation based on farmers' knowledge. Hence, there might be the possibility that the 
Fig. 4 Perceived threats of an implementation of a biochar system and their perceived severity of impact on the livelihood of farmers in Chandagalu and Manoor $(1=$ none, $2=$ low, $3=$ medium, $4=\mathrm{a}$ lot, $5=$ huge). The solid, dark red line represents the results from Chandagalu $(N=28)$. The dashed, purple line shows the results from Manoor $(N=26)$

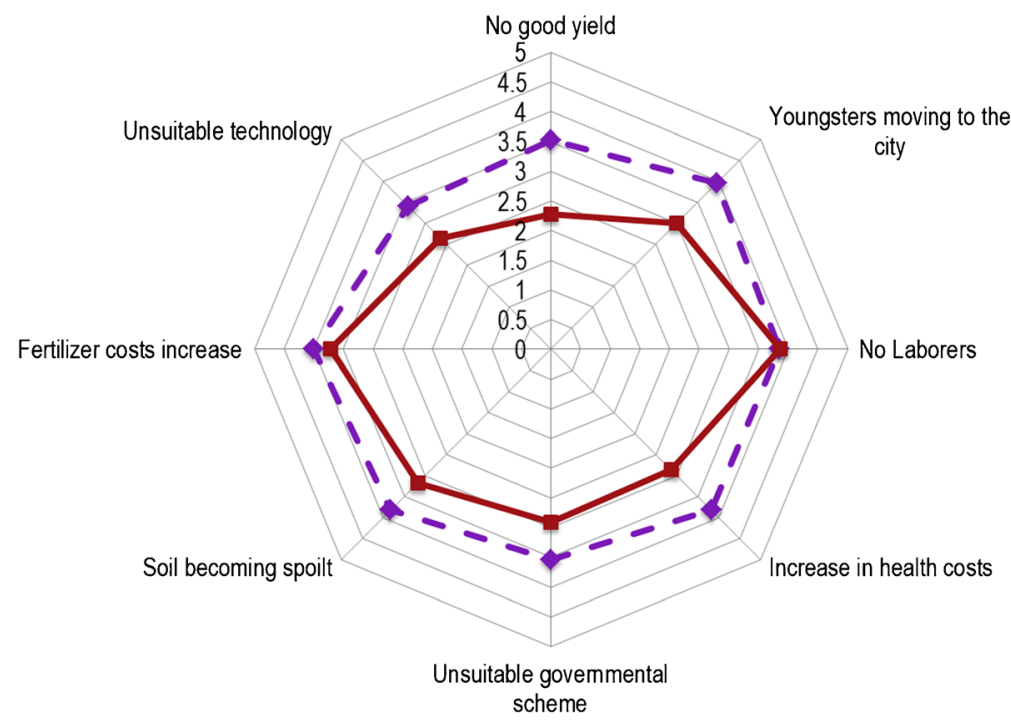

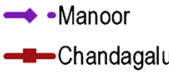

ecological system is reacting differently than expected to a biochar application, which might materialize different threats and different required adaptation capacities (Berrouet et al. 2018).

Nonetheless, this sensitivity assessment exemplarily shows that social-ecological systems differ in their ability or sensitivity to change, which in particular has to be considered while designing a biochar system and its implementation. In this study, the system (Manoor), in which farmers might be easier to get convinced to implement a biochar system, can be considered to be more prone to negative system change, whereas the system (Chandagalu) in which a biochar system adoption might be slower, is very likely more robust while facing technology failure. This confirms that for a successful biochar system implementation, more than simply technology acceptance or adoption are needed to consider but also the adaptation capacity or the ability of individuals and communities to cope with, prevent, and react to potential risks and dynamic changes (Robert et al. 2016; Smit and Wandel 2006; Tang et al. 2013).

The resilience, vulnerability, and sensitivity assessments confirm the place-specificity of any sustainable biochar system implementation (Jeffery et al. 2015; Smit and Wandel 2006; Tang et al. 2013) that is dependent not only to physical or economic (Abiven et al. 2014; Mekuria et al. 2013) but also to social and cultural conditions, characteristics, and dynamics. The assessments show that different adaptation barriers to a biochar system implementation persist in each place, and their relevance varies, which is why different biochar system designs and implementation approaches have to be considered in dependence of a combined consideration of the specific place characteristics, conditions, and dynamics, instead of only focusing on physical or economic aspects. In Manoor, in particular, a small-scale biochar system implementation design that is emphasizing the enhancement of nutrient availability in soils might be most suitable, because accessibility to required livelihood assets, such as organic waste, capital, farm management, labor, and trust, is perceived to be higher than in Chandagalu. In Manoor, it might be easier to find farmers who want to try a biochar system, because of their more pro-active tendency. However, because they show reactive strategies to failure, which would increase rather than decrease vulnerability, a biochar system should not be implemented too quickly or too broadly. We suggest here to implement systems step-by-step, certainly not on the land of an individual but rather on a shared piece of community land and to develop governmental schemes to support implementation in an inclusive and participatory manner.

The farmers of Chandagalu report less pro-active strategies than those of Manoor and also few reactive strategies, but nonetheless, the farmers of Chandagalu perceive themselves as less sensitive to failure. This is mirrored by the perception of being highly dependent on external circumstances, which they perceive to be unchangeable and thus to be endured. Given by the general low pro-active strategies and low trust in new technologies, the social and cultural barriers to implement a small-scale biochar system are particularly high in Chandagalu. However, the resilience assessment showed that a biochar system nonetheless might have the potential to improve the resilience of Chandagalu, for instance, by decreasing dependence on irrigation. A sustainable implementation therefore should be conducted in a manner that enables farmers in Chandagalu to increase their perception of selfefficacy and autonomy. Since they show an overall lack of trust in governmental bodies, it might be more suitable for Chandagalu to introduce a large-scale biochar system, in which farmers form cooperatives with regional industries.

The knowledge of the biochar research community about the physical requirements for successful biochar production and application for specific places is already quite advanced 
(Camps-Arbestain et al. 2015). Only few studies yet considered the economic, social, and cultural requirements and those who did often reproduce the imperative of economic return as the most important success factor (Gwenzi et al. 2015; Latawiec et al. 2017; Mekuria et al. 2013). In this research study, we could illustrate that a holistic concept, such as the social-ecological system combined with methods that enable to assess and integrate local knowledge, has the potential to support design considerations of biochar systems that integrate not only acceptance or adoption but also potential adaptation barriers. It may also direct future research on biochar system implementation, and novel technology implementation in general, to consider above all procedural aspects, because they seem to have a particular effect on the resilience and vulnerability of individuals and communities independent from place or type of technology.

\section{Conclusions}

The multi-tiered theoretical and methodical approach that we used in this research study enabled us to consider several aspects of implementing a biochar system in a tropical and developing region, which were seldom studied yet in an integrative and radically local knowledge-based manner by the biochar research community. We were able not only to show which are the most relevant aspects to be considered for the sustainable implementation of a biochar system in these regions but also to deduce specific design indications that embed the specific place conditions, characteristics, and dynamics of the selected research sites.

We showed that the potential exists to increase the systemic resilience of farming-based villages in Karnataka, South India, especially by implementing small-scale biochar systems. Nonetheless, a small-scale biochar system might not be the best option for every village. Perceptions of livelihood asset access and dependence and trust on governmental bodies should be considered, and a large-scale system may be preferable in some communities.

Our approach is a completely new angle on the implementation of biochar systems and on new technologies in agriculture in general. While many studies consider yield improvement or economic return to be the only lever to consider, we show here that a more holistic investigation is needed. In our study, while positive impacts of a biochar system implementation on the soil quality and yield of both villages are likely, the past experiences of the community and their relationships to their resources and their government completely change the conditions required for sustainable biochar system development. The approach we proposed here, while relatively time consuming, appears to be a successful method for investigating the complexity of the economic, social, and cultural structures of specific places. Combined with agronomical and biogeochemical evaluations, our new approach could provide the basis for sustainable implementation of biochar in agriculture.

Acknowledgments Foremost, we thank all the local interviewees proving us with valuable information. Further, we thank the staff of the Department of Soil Science and Agricultural Chemistry, University of Agricultural Sciences, Bangalore, India for their hospitality and their efforts in enabling local contacts and Rajani Mandhyam Chennu for her excellent translation work.

Funding information

The InnoPool Fund of the Department of Geography, University of Zurich, Switzerland provided financial support.

Data availability The datasets generated during and/or analyzed during the current study are available from the corresponding author on reasonable request.

\section{Compliance with ethical standards}

Conflict of interest The authors declare that they have no conflict of interest.

\section{References}

Abiven S, Schmidt MWI, Lehmann J (2014) Biochar by design. Nat Geosci 7:326 EP. https://doi.org/10.1038/ngeo2154

Adger WN (2006) Vulnerability. Glob Environ Chang 16:268-281. https://doi.org/10.1016/j.gloenvcha.2006.02.006

Adger WN, Kelly PM (1999) Social vulnerability to climate change and the architecture of entitlements. Mitig Adapt Strateg Glob Chang 4: 253-266. https://doi.org/10.1023/A:1009601904210

Amjath Babu TS (2008) Economic and environmental impacts of political non-cooperative strategies in water management: an analysis of prospective policies in the Cauvery River basin of India. Dissertation, Justus-Liebig University Giessen

Barrow CJ (2012) Biochar: potential for countering land degradation and for improving agriculture. Appl Geogr 34:21-28. https://doi.org/10. 1016/j.apgeog.2011.09.008

Berrouet LM, Machado J, Villegas-Palacio C (2018) Vulnerability of socio-ecological systems: a conceptual framework. Ecol Indic 84:632-647. https://doi.org/10.1016/j.ecolind.2017.07.051

Camps-Arbestain M, Amonette JE, Singh B, Wang T, Schmidt HP (2015) A biochar classification system and associated test methods. In: Lehmann J, Joseph S (eds) Biochar for environmental management: science, technology and implementation. Routledge, Taylor and Francis Group, London and New York, pp 165-193

Coomes OT, Miltner BC (2017) Indigenous charcoal and biochar production: potential for soil improvement under shifting cultivation systems. Land Degrad Dev 28:811-821. https://doi.org/10.1002/ldr. 2500

Crane-Droesch A, Abiven S, Jeffery S, Torn MS (2013) Heterogeneous global crop yield response to biochar: a meta-regression analysis. Environ Res Lett 8:44049. https://doi.org/10.1088/1748-9326/8/4/ 044049

Ding Y, Liu Y, Liu S, Li Z, Tan X, Huang X, Zeng G, Zhou L, Zheng B (2016) Biochar to improve soil fertility. A review. Agron Sustain Dev 36:1856. https://doi.org/10.1007/s13593-016-0372-z

Duku MH, Gu S, Hagan EB (2011) Biochar production potential in Ghana-a review. Renew Sust Energ Rev 15:3539-3551. https:// doi.org/10.1016/j.rser.2011.05.010 
Eden C (1994) Cognitive mapping and problem structuring for system dynamics model building. Syst Dyn Rev 10:257-276. https://doi. org/10.1002/sdr.4260100212

Frausin V, Fraser JA, Narmah W, Lahai MK, Winnebah TRA, Fairhead J, Leach M (2014) "God made the soil, but we made it fertile": gender, knowledge, and practice in the formation and use of African dark earths in Liberia and Sierra Leone. Hum Ecol 42:695-710. https:// doi.org/10.1007/s10745-014-9686-0

Gallopín GC (2006) Linkages between vulnerability, resilience, and adaptive capacity. Glob Environ Chang 16:293-303. https://doi.org/10. 1016/j.gloenvcha.2006.02.004

Glaser B, Lehmann J, Zech W (2002) Ameliorating physical and chemical properties of highly weathered soils in the tropics with charcoal a review. Biol Fertil Soils 35:219-230. https://doi.org/10.1007/ s00374-002-0466-4

Gray SRJ, Gagnon AS, Gray SA, O’Dwyer B, O'Mahony C, Muir D, Devoy RJN, Falaleeva M, Gault J (2014) Are coastal managers detecting the problem?: assessing stakeholder perception of climate vulnerability using fuzzy cognitive mapping. Ocean Coast Manag 94:74-89. https://doi.org/10.1016/j.ocecoaman.2013.11.008

Gwenzi W, Chaukura N, Mukome FND, Machado S, Nyamasoka B (2015) Biochar production and applications in sub-Saharan Africa: opportunities, constraints, risks and uncertainties. J Environ Manag 150:250-261. https://doi.org/10.1016/j.jenvman.2014.11.027

Jeffery S, Bezemer TM, Cornelissen G, Kuyper TW, Lehmann J, Mommer L, Sohi SP, van de Voorde TFJ, Wardle DA, van Groenigen JW (2015) The way forward in biochar research: targeting trade-offs between the potential wins. GCB Bioenergy 7: 1-13. https://doi.org/10.1111/gcbb.12132

Jeffery S, Abalos D, Prodana M, Bastos AC, van Groenigen JW, Hungate BA, Verheijen F (2017) Biochar boosts tropical but not temperate crop yields. Environ Res Lett 12:53001. https://doi.org/10.1088/ 1748-9326/aa67bd

Latawiec A, Królczyk J, Kuboń M, Szwedziak K, Drosik A, Polańczyk E, Grotkiewicz K, Strassburg B (2017) Willingness to adopt biochar in agriculture: the producer's perspective. Sustainability 9:655. https:// doi.org/10.3390/su9040655

Leach M, Fairhead J, Fraser J (2012) Green grabs and biochar: revaluing African soils and farming in the new carbon economy. J Peasant Stud 39:285-307. https://doi.org/10.1080/03066150.2012.658042

Lehmann J, Joseph S (2015) Biochar for environmental management: an introduction. In: Lehmann J, Joseph S (eds) Biochar for environmental management: science, technology and implementation. Routledge, Taylor and Francis Group, London and New York, pp $1-13$

McHenry MP (2009) Agricultural bio-char production, renewable energy generation and farm carbon sequestration in Western Australia: certainty, uncertainty and risk. Agric Ecosyst Environ 129:1-7. https:// doi.org/10.1016/j.agee.2008.08.006
Mekuria W, Getnet K, Noble A, Hoanh CT, McCartney M, Langan S (2013) Economic valuation of organic and clay-based soil amendments in small-scale agriculture in Lao PDR. Field Crop Res 149: 379-389. https://doi.org/10.1016/j.fcr.2013.05.026

Moser CON (1998) The asset vulnerability framework: reassessing urban poverty reduction strategies. World Dev 26:1-19. https://doi.org/10. 1016/S0305-750X(97)10015-8

Mukherjee A, Lal R (2014) The biochar dilemma. Soil Res 52:217. https://doi.org/10.1071/SR13359

Özesmi U, Özesmi SL (2004) Ecological models based on people's knowledge: a multi-step fuzzy cognitive mapping approach. Ecol Model 176:43-64. https://doi.org/10.1016/j.ecolmodel.2003.10.027

Robert M, Thomas A, Bergez J-E (2016) Processes of adaptation in farm decision-making models. A review. Agron Sustain Dev 36:21. https://doi.org/10.1007/s13593-016-0402-x

Shackley S, Carter S, Sims K, Sohi S (2011) Expert perceptions of the role of biochar as a carbon abatement option with ancillary agronomic and soil-related benefits. Energy Environ 22:167-187. https://doi.org/10.1260/0958-305X.22.3.167

Smit B, Wandel J (2006) Adaptation, adaptive capacity and vulnerability. Glob Environ Chang 16:282-292. https://doi.org/10.1016/j. gloenvcha.2006.03.008

Sohi S, McDonagh J, Novak J, Weixiang W, Miu L-M (2015) Biochar systems and system fit. In: Lehmann J, Joseph S (eds) Biochar for environmental management: science, technology and implementation. Routledge, Taylor and Francis Group, London and New York, pp 737-761

Spokas KA, Cantrell KB, Novak JM, Archer DW, Ippolito JA, Collins HP, Boateng AA, Lima IM, Lamb MC, McAloon AJ, Lentz RD, Nichols KA (2012) Biochar: a synthesis of its agronomic impact beyond carbon sequestration. J Environ Qual 41:973-989. https:// doi.org/10.2134/jeq2011.0069

Tang Q, Bennett SJ, Xu Y, Li Y (2013) Agricultural practices and sustainable livelihoods: rural transformation within the Loess Plateau, China. Appl Geogr 41:15-23. https://doi.org/10.1016/j.apgeog. 2013.03.007

Thiault L, Marshall P, Gelcich S, Collin A, Chlous F, Claudet J (2018) Mapping social-ecological vulnerability to inform local decision making. Conserv Biol 32:447-456. https://doi.org/10.1111/cobi. 12989

Vanwindekens FM, Baret PV, Stilmant D (2014) A new approach for comparing and categorizing farmers' systems of practice based on cognitive mapping and graph theory indicators. Ecol Model 274:111. https://doi.org/10.1016/j.ecolmodel.2013.11.026

Publisher's note Springer Nature remains neutral with regard to jurisdictional claims in published maps and institutional affiliations. 